\title{
Agrupacions musicals a la Comunitat Valenciana i Catalunya: agents per al desenvolupament sociocultural
}

\author{
Salvador Oriola Requena * \\ Josep Gustems Carnicer ${ }^{* *}$ \\ Joan Santacana Mestre ${ }^{* * *}$
}

\section{Resum}

Les bandes a la Comunitat Valenciana i les corals a Catalunya conformen dos fenòmens d'associacionisme musical amateur referents tant a nivell nacional com internacional. El present article, realitzat a partir d'una exhaustiva revisió bibliogràfica de tipus multidisciplinari, consisteix en un estudi descriptiu amb el qual es pretén mostrar com les funcions socioculturals que han exercit les dues tipologies d'agrupacions, des dels seus orígens fins a l'actualitat, han anat en augment tant en quantitat com en qualitat. Per això s'ha realitzat una retrospectiva històrica en la que es pot observar com ha anat evolucionant aquest fenomen fins arribar al moment d'esplendor actual. Tot aquest progrés ve avalat per l'existència de 547 bandes a la Comunitat Valenciana i més de 900 corals a Catalunya, les quals s'han convertit amb els anys en un referent identitari, cultural, social, educatiu i patrimonial de primer ordre.

\section{Paraules clau}

Agrupacions musicals, bandes, corals, desenvolupament sociocultural.

Recepció original: 9 d'octubre de 2019

Acceptació: 24 d'abril de 2020

Publicació: 1 de juny de 2021

\section{Introducció}

La música i les agrupacions musicals han estat presents en totes les societats conegudes exercint múltiples funcions, les quals han anat variant a través del temps per adaptar-se a les necessitats de cada moment i cada lloc (Merriam, 1992). La societat digital actual es caracteritza per l'ús massiu de noves tecnologies, la interconnectivitat global i l'accés a tot tipus de música, des de qualsevol lloc en qualsevol moment. Tot això ha contribuït de manera notòria a l'expansió de la música i l'increment de les seves funcions.

Al context espanyol, tots aquests avenços han repercutit lògicament en la creació, consolidació i difusió de tot tipus de gèneres i agrupacions musicals. No obstant això, hi ha dos fenòmens associatius que ja abans de l'esmentada revolució digital i la seva contribució a la música, posseïen una folgada tradició musical: les bandes a la Comunitat

$\left(^{*}\right) \quad$ Titulat superior en música, mestre, llicenciat en Història i Ciències de la Música i doctor en Educació. És professor associat de Didàctica de l'Expressió Musical a la Facultat d'Educació de la Universitat de Barcelona. Les seves principals línies de recerca són l'educació musical, les agrupacions musicals i l'educació emocional. Adreça electrònica: salvaoriola@ub.edu

$(* *) \quad$ Titulat superior en música, mestre, llicenciat en Antropologia i doctor en Pedagogia. És professor titular de Didàctica de l'Expressió Musical a la Facultat d'Educació de la Universitat de Barcelona. Les seves principals línies de recerca són l'educació musical i la música com experiència artística i simbòlica. Adreça electrònica: jgustems@ub.edu

$\left({ }^{* * *}\right) \quad$ Llicenciat en Filosofia i Lletres i doctor en Pedagogia. És professor titular de Didàctica de les Ciències Socials a la Facultat d'Educació de la Universitat de Barcelona. La seva àmplia obra científica i divulgativa comprèn més de 900 publicacions entre llibres, quaderns i articles. Adreça electrònica: jsantacana@ub.edu 
Valenciana i les corals a Catalunya. Dos fenòmens exemplars d'associacionisme musical amateur que compten amb més de 150 anys de trajectòria i que amb el pas del temps s'han consolidat com a agents capitals pel que fa a la seva funcionalitat tant social com artística i cultural. Bandes i corals s'han convertit en símbols identitaris i patrimonials d'ambdós territoris, els seus habitants s'identifiquen amb ells i se senten orgullosos dels seus èxits (Carbonell, 2000a; Cohen, 1997; Oriola, Gustems i Filella, 2019; Roda, 2001). Per això no és estrany que la Comunitat Valenciana i Catalunya encapçalin el rànquing d'autonomies espanyoles amb major nombre d'agrupacions musicals integrades per afeccionats (Fernández, Corraliza i Ferreres, 2017; Ministerio de Educación, Cultura y Deporte, 2016).

Aquesta exemplaritat traspassa fronteres, ja que en l'actualitat moltes de les agrupacions musicals que conformen els dos fenòmens estudiats són referents mundials, no només pels seus fins artístic-culturals sinó també per la seva contribució a la millora de múltiples aspectes relacionats, com ara activitats acadèmiques (Reyes, 2010) o competències socioemocionals (Ferrer, 2011). D'acord amb múltiples recerques, la interpretació musical col-lectiva, principal objectiu de les esmentades agrupacions, pot repercutir positivament en l'augment del benestar (Calderón-Garrido, Martín-Piñol, Gustems-Carnicer i Portela-Fontán, 2018), la integració social (Benavides i Pérez, 2002), el desenvolupament cognitiu (Gustems, 2001; Hallam i Creech, 2010; Guhn, Emerson i Gouzouasis, 2019), etc.

Coneguda la importància tant cultural com social que exerceixen aquestes tipologies d'agrupacions, és necessari i interessant indagar sobre com es van gestar i han evolucionat ambdós fenòmens. La música, com a component del complex cultural de qualsevol grup humà, mai sol ser una variable independent d'aquest. Les relacions existents entre la música i la resta d'elements culturals presents en tota societat no són aleatòries i responen a patrons integrats; qualsevol manifestació artística, tant musical com visual o plàstica, només és comprensible si s'analitza el context que li va donar origen i on va créixer. Per aquesta raó el present treball té com a objectiu mostrar la funció sociocultural que han exercit les bandes a la Comunitat Valenciana i les corals a Catalunya des dels seus orígens fins a l'actualitat. Per a això s'ha dut a terme un estudi descriptiu, fonamentat en una exhaustiva revisió bibliogràfica de tipus multidisciplinari i, tot això, contrastat amb l'experiència professional dels autors.

\section{Fonaments de l'associacionisme musical}

L'auge de les músiques populars a Europa és un fenomen estretament vinculat amb els moviments romàntics i nacionalistes. El romanticisme, com a fenomen social, precedeix als moviments artístics que van adoptar aquest nom; a la fi del segle XVIII i com a herència del classicisme, sorgeix un interès sobtat per part de l'aristocràcia pels temes populars, la vida camperola a l'aire lliure i sobretot per una tendència a valorar allò «pastoral» (Craveri, 2018). En aquest sentit es van gestar moltes idees estètiques en el camp de l'arquitectura, la jardineria, la decoració d'interiors o la literatura que significaven un qüestionament del racionalisme i del cientifisme que s'imposava a través del moviment il.lustrat.

Va ser sobre aquest fons cultural de les elits europees que es va superposar el moviment romàntic a la fi del segle XVIII i que va dominar de forma gairebé absoluta tota la primera meitat del segle XIX. El seu bressol va ser Anglaterra i des d'allà va saltar a l'Europa continental, especialment als estats alemanys, afectant tots els aspectes de la vida i totes les arts. La música seria un camp especialment fèrtil pel moviment romàntic doncs, més 
que qualsevol altra expressió de bellesa, la música afecta els sentiments íntims. I aquest primer romanticisme va estar en la base dels moviments nacionals i revolucionaris que van sacsejar el segle.

Tots aquests moviments nacional-romàntics es van basar en dos grans corpus ideològics: d'una banda un nacionalisme que partia de la suposició que l'esperit dels pobles era semblant a una vinya que, en funció del sòl on arrela i de l'aire que respira, dóna els seus fruits, de manera que la llengua resultava fonamental ja que era l'expressió de l'esperit del poble; en segon Iloc, un nacionalisme resultant de les revolucions burgeses que implicaven la creença que la nació és, en essència, el conjunt de ciutadans que accepten viure sota unes idèntiques normes que ells mateixos s'han atorgat, les seves constitucions. Però, sigui quina sigui l'arrel del moviment nacional-romàntic, les essències de la nació calia buscar-les en el poble, el Volk, els seus contes i llegendes, les seves tradicions religioses, el seu passat gloriós, o les seves músiques i els seus instruments específics; fou llavors quan les músiques populars es van recopilar en una tasca ingent d'investigació lingüística i etnogràfica, es van crear bandes que utilitzaven instruments que fins llavors gairebé havien estat menyspreats o oblidats i sobretot, això va arrelar en les classes populars, especialment en els sectors més dinàmics de l'artesanat urbà i també en la naixent classe obrera.

Plantejar-se el paper de la classe obrera en aquest fenomen cultural no és un tema menor; els obrers que començaven a engolir mines i fàbriques des d'edats primerenques eren camperols arrencats de la «vida campestre» per la fam i per avidesa de diners de la burgesia industrial. Arribaven als lúgubres llocs de treball, desvalguts de recursos però no orfes de música; res més lògic que fossin ells els que alimentessin les naixents societats musicals que, sota fórmules diverses de bandes, corals i fins i tot orquestres van anar naixent en aquells llocs on la industrialització destruïa els últims reductes de la vida rural: a Catalunya i a València, de la mateixa manera que estava passant a Renània, Saxònia, Prússia, Piemont i altres tantes terres del Vell Continent.

És ben sabut que aquests moviments a l'Espanya del segle XIX van arribar tard; sense una revolució burgesa important, una industrialització lenta i desigual; la desamortització de béns no va crear una burgesia industrial sinó, en moltes ocasions, una neo-aristocràcia rural; tan sols en algunes zones del país hi va haver una autèntica industrialització que va sobreviure al poder de l'Església i de les classes dirigents: Catalunya i València van ser dos d'aquests territoris on parcialment van arrelar la revolució industrial i la burgesia.

La producció i la difusió de la música a Espanya fins a mitjan segle XIX van anar a càrrec, pràcticament en la seva totalitat, de l'Església, l'Exèrcit i alguns pocs músics independents que s'encarregaven d'actuar al carrer i també d'entretenir els membres de la Cort i l'alta societat. Amb l'arribada de la revolució industrial i els canvis socioeconòmics que la van acompanyar, la producció i el consum musical, reservat en aquells temps per només uns pocs, va passar a convertir-se gradualment en un element accessible per a gran part de la població (Asensi, 2013).

L'Església i l'Exèrcit que fins a principis del segle XIX havien exercit el monopoli pel que fa a l'educació i difusió musicals, van començar a ser reemplaçats per entitats privades i associatives promogudes per la nova burgesia i les classes mitjanes. En aquesta època l'associacionisme viu un moment d'esplendor, de fet, ressorgeixen i es funden un elevat nombre de societats filharmòniques, ateneus, liceus i acadèmies, com ara el Liceo 
Dramático de Aficionados, fundat a Barcelona el 1837, el qual anys més tard passaria a convertir-se en el primer conservatori d'aquesta ciutat; o la Real Sociedad Económica de Amigos del País de Valencia, responsable de la fundació del Conservatori de la ciutat de València el 1879 (Aviñoa, 2000). L'aparició d'aquests primers conservatoris estatals simbolitzarà la gènesi de la institucionalització dels ensenyaments artístics a Espanya. Tant les noves associacions com els conservatoris es van proposar com a objectiu principal incrementar l'oferta musical, per donar resposta a una àmplia demanda d'educació musical existent en aquesta època, a causa de la consideració de l'art musical com a signe de prestigi social, una possible sortida laboral, i un element per a l'oci, que amb les millores laborals dels obrers aniria en augment.

Totes aquestes particularitats que es donen al llarg del segle XIX seran el fonament a partir del qual s'originaran tant el fenomen coral a Catalunya com el de les bandes instrumentals en el llevant valencià. La ciutat de Barcelona, seguint el monopoli cultural que tenien les principals ciutats europees, es va convertir en l'epicentre del fenomen coral català; en canvi, el moviment de les bandes a València no va tenir un epicentre tan definit, sent els pobles del món rural els veritables embrions d'aquest fenomen, com alternativa a la limitada oferta cultural i d'oci que es donava en ells (Asensi, 2010).

\section{Gènesi del fenomen coral a Catalunya}

La gènesi del moviment coral català no es pot estudiar com una variable independent del sorgiment d'altres institucions similars, com va ser el cas dels ateneus, que també van emergir a Catalunya durant el segon terç del segle XIX; aquest procés es va estructurar en el si d'una societat en la qual les relacions socials capitalistes van condicionar l'economia i la mentalitat de les noves classes socials. Aquest escenari es va anar desenvolupant immers en un dur i llarg procés d'industrialització; durant aquest període formatiu de les societats industrials, en els nuclis urbans, però també a les zones rurals subjectes a la mateixa dinàmica, les lluites sociopolítiques van fer necessaris nous espais de sociabilitat. És en aquest context on sorgeixen «societats» que tenen com a objectiu aglutinar voluntats al voltant d'imatges mentals i idearis en àmbits tan diversos com la cultura, l'oci, l'esport, l'excursionisme i, òbviament, el cant coral.

El resultat de tot aquest complex procés d'associacionisme tant en àmbits rurals com urbans a Catalunya és interessant per a nosaltres ja que situa l'associacionisme coral en la seva justa mesura. Segons Arnabat i Ferré (2017), i partint de les dades estadístiques existents, es van registrar entre 1836 i 1936 de manera general a Catalunya 1.746 entitats culturals, instructives i / o recreatives, de les quals 986 (un 56,5\%) eren d'esbarjo i 760 (un $43,5 \%)$ culturals i instructives. Si atenem a les seves denominacions, les clàssiques d'ateneo i casino representen conjuntament una quarta part del total: 267 associacions (un 15,5\%) s'anomenen ateneus i 140 (un 8\%) casinos. Una altra quarta part de les entitats, 416, es denominen «centres» i 280 (un 16\%) es «societats»; a continuació trobem els «cercles» (184 entitats, un 10,5\%), les corals i els orfeons (94, un 5,5\%), els «casals» $(58$, un $3 \%)$ i les associacions (29, un 1,5\%). A més, 278 entitats (un 16\%) tenen altres denominacions (unions, foments, patronats, agrupacions, germandats, grups i altres).

El fenomen coral català neix a la ciutat de Barcelona a partir de la fundació de dues corals: la societat coral obrera La Fraternitat, fundada el 1850 per Josep Anselm Clavé, republicà federal i l'Orfeó Barcelonès fundat el 1853 pels germans Tolosa. Clavé va crear La Fraternitat amb l'objectiu no només de gaudir i divulgar la música, sinó anar més enllà 
i convertir les agrupacions vocals en una eina per a la dignificació i reconeixement de la classe obrera; en canvi, els germans Tolosa li van donar un altre enfocament, doncs a més de proposar-se apropar la música a tothom, també pretenien aconseguir un bon resultat artístic a través de la formació acadèmic-musical dels seus components.

Els cors de Clavé es van desenvolupar en paral-lel al moviment ateneístic, en una ràpida progressió, de manera que el 1867 ja funcionaven a Catalunya 106 corals i a finals de la dècada dels setanta del segle XIX, el cant coral reunia a uns 40.000 obrers i camperols a les comarques catalanes. Aquest fet no feia res més que situar les corals en el marc de relacions amb associacions afins com els ateneus. Per tant, des de la seva fundació van tenir una ràpida acceptació entre la població, doncs utilitzaven elements de tradició popular (cançons per al treball, de bressol, religioses...), que no requerien d'una gran formació ni inversió econòmica, per aconseguir uns fins socials en què les classes populars eren espectadores i intèrprets al mateix temps. Per aquesta raó La Fraternitat, que anys més tard de la seva creació, per causes polítiques va canviar el seu nom pel d'Euterpe, es va consolidar com un destacat element cultural i de cohesió social que es va estendre per tot Catalunya. Prova d'això va ser la necessitat de crear a 1860, I'Associació Euterpense, una entitat associativa per a la coordinació i el bon funcionament de totes les corals claverianes. En canvi, l'Orfeó Barcelonès des dels seus inicis, tot i gaudir de la protecció de l'Ajuntament de la ciutat per tal de contrarestar l'èxit creixent de les societats corals de caire republicà creades per Clavé, no va tenir tanta repercussió, entre d'altres raons, per programar un repertori culte pel qual no existia una audiència preparada i la manca de renovació d'aquest (Carbonell, 2000a).

Els cors de Clavé, juntament amb les societats creades a la seva semblança, després de dues dècades d'èxit popular van començar a decaure a causa de diferents esdeveniments socials i polítics com una major dedicació a la política per part de J. A. Clavé, la crisi econòmica del 1865, l'estatisme pel que fa a la formació i el repertori musical, la proclamació del final de la primera República el 1874 o la mort setmanes més tard del propi Clavé (Carbonell, 2000b). D'acord amb Carbonell, després d'aquesta crisi:

\footnotetext{
A poc a poc l'activitat coral es va anar reprenent, i encara que no s'arribés a l'eufòria dels anys 1860, es va recuperar una certa estabilització de l'activitat, això sí, agreujada per les lluites internes en el si de l'Associació Euterpense, l'organisme federatiu que agrupava els cors claverians fundat per Clavé el 1860, amb les conseqüents escissions i reagrupacions diverses que van marcar la vida coral claveriana fins a 1936. La crisi també es va deixar veure en el terreny musical. Els Cors de Clavé es van tancar en una endogàmia, un culte a la personalitat, venerant i mitificant al fundador, a la tradició heretada, i negant tota possibilitat de renovació, tant de repertoris com de plantejaments musicals. El resultat és conegut (Carbonell, 2003, p. 495).
}

La celebració a la ciutat comtal de l'Exposició Universal el 1888 va suposar un fort revulsiu econòmic, cultural i social. Pel que fa a la vida musical catalana, aprofitant l'impuls de l'esmentat esdeveniment, es van celebrar diferents festivals i concursos corals, servint tot això d'estímul per reformar les agrupacions de Clavé que, com s'ha esmentat anteriorment, havien perdut tot el seu esplendor, i també per inspirar la creació de noves agrupacions vocals com l'Orfeó Català, fundat el 1891 pels joves músics Amadeu Vives i Lluís Millet. Foren anys de gran activitat cultural, tal com ho demostren la fundació de diferents alternatives corals de menor relleu com ara la Societat Coral Catalunya Nova fundada el 1896 per Enric Morera, a causa d'una escisió de l'entitat claveriana Societat Coral Euterpe (Artís, 1990; Aviñoa, 2009). 
En l'última part del segle XIX s'observa clarament com el moviment coral català, a més de perseguir una significativa formació i difusió de l'art musical, va passar a ser un clar reflex dels corrents ideològics dominants del moment. D'una banda, hi havia els cors de Clavé, centrats en formar, entretenir i proporcionar oci als obrers, i d'altra banda, l'Orfeó Català, de caràcter nacionalista conservador, format per persones de classe benestant amb preparació cultural i musical, amb un variat repertori conformat per cançons d'exaltació patriòtica, música religiosa, cançons tradicionals i música simfonico-coral europea. Aquest últim, malgrat adoptar l'estructura i la dinàmica associativa claveriana, va proposar des de la seva fundació uns objectius basats en l'exaltació de l'esperit català juntament amb la necessitat d'aconseguir un elevat nivell artístic a partir de la creació d'un estil propi.

Aquests objectius casaven perfectament amb els ideals promulgats pel corrent cultural del Modernisme, de manera que l'Orfeó es va consolidar com la formació de moda de la primera part del segle Xx. L'admiració per aquesta institució va repercutir i va influir en la creació a la seva semblança d'agrupacions corals arreu de la geografia catalana com I'Orfeó de Sants (1899), I'Orfeó Barceloní (1900), I'Orfeó Lleidatà (1902), l'Orfeó Mataroní (1903), I'Orfeó Gracienc (1904) o l'Orfeó Tortosí (1905), entre molts d'altres. El 1918 el moviment orfeonista comptava amb més de 62 entitats, per la qual cosa es va decidir crear una federació sota el nom de Germanor dels Orfeons de Catalunya amb l'objectiu de millorar la coordinació referent al funcionament i al treball artístic-patriòtic entre les entitats federades. Amb els anys es va anar incrementant el nombre d'orfeons federats arribant al seu màxim apogeu el 1920, quan es van comptabilitzar més de 80 orfeons. A partir d'aquest moment, les diferents oscilacions polítiques que van acabar desembocant en la Guerra Civil, van afectar a l'estabilitat i el bon funcionament del moviment orfeonista, disminuint el nombre d'agrupacions i la seva activitat artística (Narváez, 2005).

\section{Gènesi del fenomen de les bandes a la Comunitat Valenciana}

Pel que fa a l'origen del fenomen bandístic a València, no es té constància d'un inici tan concret i documentat com el de les agrupacions corals catalanes, sinó que es dona de forma gradual al Ilarg de tot el segle XIX, especialment en el seu últim terç i primeres dècades del segle $\mathrm{xx}$ amb la fundació de les primeres bandes municipals de caràcter aficionat que més tard es convertiran en Societats Musicals d'àmbit local (Astruells, 2003).

És gairebé impossible conèixer amb exactitud totes les raons que justifiquen el naixement del fenomen bandístic al llevant espanyol, en tractar-se d'un moviment multidimensional en el qual van confluir molts elements entre els quals cal destacar (Adam, 1986; Asensi, 2010; Leal, 2014):

a) L'empremta que va deixar l'Església, contribuint a la formació musical de molts alumnes; prova d'això és l'abundant nombre de bandes els primers directors musicals i fundadors de les quals van ser persones relacionades amb l'Església com organistes, rectors, frares, sagristans, etc.; per exemple, el franciscà Francesc Albarracín va fundar el 1819 la Banda Primitiva de Llíria (València).

b) L'admiració i influència de les agrupacions militars, que van propiciar el desig de disposar d'una banda pròpia en les diferents localitats i de les que van adoptar part del repertori, uniformes, forma de desfilar, etc. Moltes de les actuals bandes tenen un origen militar, com passa en la població de Guadassuar (València), on el 
1852 existia una agrupació musical amb el nom de Compañía Filarmónica de Instrumentos Militares; o la banda de la població veïna d'Algemesí que, igual que moltes altres agrupacions, es va fundar com a banda de cornetes i tambors integrada per militars voluntaris, evolucionant amb el temps cap a un conjunt instrumental més variat.

c) La presència de professors particulars juntament amb les associacions creades per la burgesia i les classes mitjanes per donar resposta a la creixent demanda d'oci per part d'una societat cada vegada més industrialitzada, a més de la consideració de l'aprenentatge musical com a signe de prestigi social. Molts d'aquests professors eren religiosos, militars o mestres d'escola que, a més de formar músics a nivell individual també es van encarregar de fundar una agrupació instrumental en moltes poblacions, com va passar per exemple en la població d'Alberic (València), la banda de la qual va ser creada en 1852 per la mestra de l'escola local.

d) La necessitat de disposar d'agrupacions musicals pel desenvolupament de festes populars com les falles, els moros i cristians, festes patronals, processons, cercaviles, actes religiosos, etc. De fet, en la historiografia de la majoria de bandes de les tres províncies valencianes, creades al llarg del segle XIX i les primeres dècades del segle $x x$, es destaca com a principal funció la participació en actes lúdic-festius, com ara el document que testifica la participació de la banda de Barx (València) en una comparsa cristiana d'Alcoi en 1886.

e) La celebració del Certamen de Bandes de Música de la ciutat de València. Té els seus orígens en l'any 1886 en el marc de la fira taurina de juliol i va ser un esdeveniment que, a més d'afavorir la creació de noves agrupacions, va motivar a les ja existents a millorar el seu nivell artístic i d'aquesta manera poder competir amb les bandes de les poblacions de tota la regió. Malgrat ser aquest el concurs amb més renom i prestigi de la Comunitat no va ser l'únic, d'acord amb Oriola (2010), a finals del segle XIX a les festes populars de poblacions com Alcoi, Llíria o Xàtiva es van organitzar certàmens de bandes, els quals van anar augmentant en qualitat i quantitat ja entrats al segle Xx. Aquestes competicions musicals han servit, des de les primeres convocatòries, per fer créixer el sentiment d'identitat $i$ l'afició musical de la gent dels pobles, la qual admira i se sent representada per la seva banda.

f) Les condicions climatològiques van possibilitar l'actuació a l'aire lliure d'aquestes noves agrupacions, convertint el carrer en un escenari musical al qual tothom tenia accés. Fins i tot en alguns casos els carrers, places i llocs a l'aire lliure es van convertir en els primers locals d'assaig per a aquestes formacions, com va passar amb la banda de la població de Jalance (València) que va iniciar el seu camí l'any 1867 assajant els dissabtes la tarda a les hortetes de Sácaras.

Fins a l'arribada de la Guerra Civil el fenomen de les bandes va anar en ascens tant pel que fa a la fundació de noves agrupacions com per la millora del nivell artístic-musical. En canvi, durant la Guerra Civil (1936-1939) i els anys immediatament posteriors, tots dos fenòmens associatius es van veure bruscament alterats de forma negativa. D'acord amb De la Ossa (2009), la vida musical no es va paralitzar, prova d'això són les celebracions de 
concerts de tot tipus com els duts a terme per la Banda Municipal de Barcelona o l'Orquesta Sinfónica de Valencia. També ho demostra la supervivència d'alguna agrupació musical amateur, com la banda musical del poble d'Alfafar (València) la qual, tot i perdre part dels seus components a conseqüència de les hostilitats, no va paralitzar la seva activitat; o els escassos concerts de caràcter benèfic i propagandístic realitzats per algun Orfeó com el de Sants o el Gracienc. Però cal matisar que aquests casos van ser excepcionals, ja que la guerra va acabar silenciant, pràcticament en la seva totalitat, tant el fenomen coral com les bandes, ja que la gran majoria d'agrupacions es van dissoldre o van entrar en estat d'hivernació.

A manera de síntesi, pel que fa a la funció sociocultural que van exercir en els seus inicis les agrupacions musicals a Catalunya i a la Comunitat Valenciana, podem afirmar que les corals van néixer com a conseqüència de la industrialització de la ciutat de Barcelona, estenent-se per tota la geografia catalana i peninsular. Es van originar com a mitjà per a la dignificació de la classe obrera, tant a nivell de formació com d'entreteniment $\mathrm{i}$ socialització; posteriorment, amb l'arribada de la Renaixença i el Modernisme, les classes benestants van recollir el seu relleu, elevant el nivell musical dels seus integrants i convertint-lo en un signe identitari del catalanisme. En el cas de les bandes, el seu origen és més dispers, ja que es dóna de forma progressiva en les diferents poblacions que conformen tot el llevant valencià, a causa d'una interrelació de factors diversos com la influència de l'Església i l'exèrcit, l'esperit festiu de les localitats valencianes, la poca oferta cultural a les zones rurals, etc. Tal com afirma Oriola (2011, p. 26) «la gènesi d'aquest moviment no serà coetània en totes les poblacions, pel que podem trobar tants casos possibles com societats musicals existents». Malgrat que les raons originàries de tots dos fenòmens, tal com hem vist, difereixin en alguns aspectes, coincideixen en molts d'altres, com per exemple en donar resposta a la creixent demanda d'oci per part de la societat, tot aconseguint d'aquesta manera democratitzar l'art musical tant a nivell de difusió com de formació musical; o també la creació, al voltant de cadascuna de les agrupacions musicals, d'un sentiment identitari col-lectiu i de pertinença, convertint-se amb el pas dels anys en un senyal d'identitat de les dues regions (Cucó, 1993).

Tal com hem avançat, durant la guerra civil espanyola (1936-1939) es va paralitzar pràcticament tota activitat cultural.

\section{La postguerra: restabliment i evolució}

Ja a la postguerra es torna a reprendre lentament l'activitat musical amb la fundació i refundació tant de bandes com corals, les quals han perdurat, moltes d'elles, fins als nostres dies. En el cas de les agrupacions corals a Catalunya, malgrat la seva clandestinitat, els cors de Clavé van mantenir la seva activitat social a causa de la seva ideologia no independentista i els interessos del règim franquista de poder acontentar i distreure la classe obrera a través de la pràctica coral (Baltà, 2011). D'altra banda i prenent com a referent el moviment coral francès À cœur joie van començar a crear-se de forma paulatina noves formacions com l'Orfeó Laudate (1942), la Massa Coral de Terrassa (1943), I'Agrupació Polifònica de Vilafranca (1947), la Coral Sant Jordi (1947), el Cor Madrigal (1951) o la Capella Polifònica de Girona (1956) entre d'altres, i també van reiniciar la seva activitat, superant nombroses adversitats de caràcter polític, agrupacions tan il/lustres com l'Orfeó de Sants (1940), I'Orfeó Gracienc (1945) o l'Orfeó Català (1946), que amb els anys acaba- 
ran consolidant-se i convertint-se en icones de la pròspera vida coral que es desenvoluparà a Catalunya durant la segona part del segle XX (Aviñoa, 2009; Bonastre i Cortès, 2009; Ferrer, 2011).

L'aparició gradual, a partir de la dècada de 1940, de totes aquestes noves agrupacions corals al llarg de la geografia catalana i també de les bandes en tot el territori valencià, és la raó per la qual en ambdues regions es van crear federacions, amb l'objectiu d'orientar, coordinar i assessorar totes les agrupacions representades tant a nivell artístic com jurídic-administratiu. Aquest nou escenari de formació i consolidació de nombroses agrupacions vocals i instrumentals i les seves federacions es pot considerar com el punt de partida del fenomen associatiu musical actual.

En el cas de les bandes de música l'any 1968 es va constituir la Federación de Sociedades Musicales de la Comunidad Valenciana ${ }^{1}$ (FSMCV), la qual ha perdurat fins als nostres dies consolidant-se com l'única federació representativa de les societats musicals en aquesta comunitat. D'acord amb els seus estatuts:

Constituyen el objetivo de la FSMCV, la promoción y el desarrollo de las Sociedades Musicales, en todas sus vertientes, impulsando su crecimiento, diversificación y mejora, tanto en su labor pedagógica musical como en su actividad socio-cultural, prestando una especial atención al crecimiento y normalización de sus escuelas de música, a la formación musical de los jóvenes y a su educación integral, al perfeccionamiento del modelo de gestión de sus asociados y a la progresiva formación de sus directivos en tareas de gestión (FSMCV, 2019).

La situació coral a Catalunya va ser més heterogènia pel que fa a l'associacionisme federatiu. A partir de la dècada de 1950 es comencen a fundar i refundar federacions amb l'objectiu de representar i coordinar les diferents tipologies d'agrupacions vocals presents en tota la regió catalana:

a) L'any 1951 es va reorganitzar la Federació de Cors de Clavé (FCC), la qual a més de distribuir les ajudes econòmiques rebudes per institucions públiques, s'encarregarà de dinamitzar les societats federades a través d'intercanvis, formació musical, assessorament legal i artístic, etc.

b) El 1959 es constitueix el Secretariat d'Orfeons de Catalunya (SOC), considerada com a entitat hereva i regeneradora de l'abolida Germanor dels Orfeons de Catalunya, la qual en 1981, després d'una reconversió funcional i estructural, donarà origen a la Federació Catalana d'Entitats Corals (FCEC). D'acord amb el capítol II dels seus estatuts:

Les finalitats essencials de la FCEC seran impulsar i coordinar activitats de tipus col-lectiu i representatiu de les entitats federades, assessorar-les i orientar-les en tots els aspectes relatius a la seva vida musical $\mathrm{i}$

(1) Per tal de facilitar la lectura presentem una clau de sigles:

ACCG: Agrupació Coral de les Comarques de Girona

CJC: Cors Joves de Catalunya

FCC: Federació de Cors de Clavé

FCEC: Federació Catalana d'Entitats Corals

FCPC: Federació Catalana de Pueri Cantores

FSMCV: Federación de Sociedades Musicales de la Comunidad Valenciana

GIC: Grups Intermedis de Catalunya

MCC: Moviment Coral Català

SCIC: Secretariat de Corals Infantils de Catalunya

SOC: Secetariat d'Orfeons de Catalunya 
institucional, ajudar i promoure la creació de noves entitats corals, realitzar activitats formatives i creatives de música coral i editar i difondre material formatiu i divulgatiu (FCEC, 2019).

c) El 1967 neix el Secretariat de Corals Infantils de Catalunya (SCIC), creada en el si de Joventuts Musicals amb l'objectiu de representar les entitats corals més joves del territori català. Entre els seus primers objectius s'establia aportar als infants una educació musical que moltes vegades faltava a l'escola, així com la possibilitat de conèixer millor la llengua catalana a través del cant. Aquests objectius amb el temps han anat adaptant-se a les necessitats del moment i en l'actualitat persegueixen difondre repertori tradicional català i d'altres orígens, impulsar la creació de noves composicions d'obres vocals, millorar el nivell musical de les corals federades, així com l'organització i coordinació de trobades i cursos formatius diversos (SCIC, 2019).

d) El 1969 comença la seva marxa la federació de Grups Intermedis de Catalunya (GIC) que dècades més tard passarà a denominar Cors Joves de Catalunya (CJC). Aquesta associació, des dels seus inicis, pretén donar continuïtat a les agrupacions formades per joves provinents de corals infantils i es proposa promoure i coordinar el cant coral entre gent jove, d'edats que oscil.len entre els 16 i 35 anys, per millorar el nivell artístic de les agrupacions juvenils a través d'una ampliació dels seus coneixements i de les seves possibilitats musicals, socials i humanes (CJC, 2019).

e) El 1991 neix en el si de l'Església Catòlica, la Federació Catalana de Pueri Cantores (FCPC) amb l'objectiu de donar veu a les agrupacions corals que participen en els oficis litúrgics del territori català. Aquesta federació pertany al moviment internacional dels Pueri Cantores, el qual segueix l'extensa tradició de l'Església d'emprar el cant dels infants al servei de la litúrgia. A més de la seva funcionalitat religiosa, també promou la formació dels seus membres a través d'activitats complementàries com trobades i congressos internacionals, la catalanitat i la qualitat musical de les agrupacions que la formen.

f) Amb l'objectiu d'agrupar totes les federacions corals catalanes existents, el 1995 es crea el Moviment Coral Català (MCC), una confederació que, a més de coordinar totes les activitats corals de les diferents federacions que representa, vol vetllar per la seva representació a nivell internacional. Tal com afirma Ferrer (2011) gràcies a la força promoguda per la unió d'aquestes entitats es duen a terme diferents tasques com fòrums, relacions i intercanvis internacionals, etc., que garantiran la màxima presència i visibilitat del cant coral català en totes les seves dimensions, tant a nivell nacional com internacional. Des de la seva fundació hi ha hagut altes i baixes respecte a les federacions que inicialment constituïen aquesta confederació.

g) L'any 2003 neix la federació més jove existent a Catalunya sota el nom d'Agrupació Coral de les Comarques de Girona (ACCG), que es proposa fomentar i consolidar el cant coral amateur en aquesta província. Igual que les altres federacions promou la formació i la millora musical i social dels seus membres a través de trobades, seminaris, intercanvis de partitures, etc. (Ferrer, 2011).

En aquest apartat s'ha pogut comprovar com els anys de postguerra van servir per reprendre tímidament la vida musical d'aquestes entitats, i va ser a partir de la segona 
meitat de segle quan l'activitat associativa va augmentar considerablement i es va afermar gràcies a la creació i refundació de nombroses agrupacions musicals, representades i recolzades per les seves respectives federacions. Tot aquest enrenou organitzatiu serà considerat com a base fonamental a partir de la qual s'aniran fundant i consolidant les formacions actuals.

\section{Bandes i corals a l'actualitat}

Des de finals del segle xx i fins a l'actualitat, tant les bandes com les corals viuen una època d'esplendor, tal com reflecteixen la nombrosa quantitat d'agrupacions i l'elevat nivell artístic-musical que van assolint moltes d'aquestes agrupacions.

Segons l'últim cens realitzat per la FSMCV a l'any 2015 el fenomen de les bandes a la Comunitat Valenciana està conformat per més de 540 societats inscrites, amb un volum de socis aproximat de 200.000 persones, més de 40.000 músics federats i al voltant de 150.000 persones vinculades. Cada societat, a més d'una banda adulta, també acull diferents agrupacions complementàries, tal com es mostra a la Figura 1.

\section{Figura 1. Agrupacions musicals de les societats federades a la FSMCV (2015)}

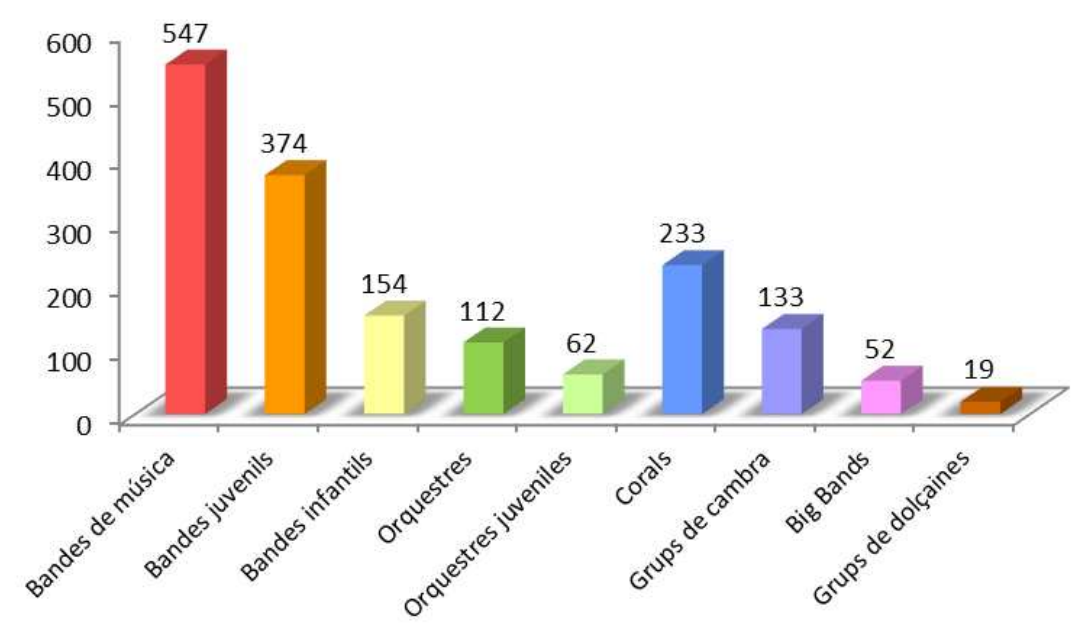

Pel que fa a la infraestructura d'aquestes societats, Roda (2001) ho sintetitza de la manera següent:

1. Personal i organització: directives, socis, personal de servei.

2. Aspectes i grups artístics: directors o directores, professors de les escoles d'educands, músics i els diferents tipus d'agrupacions de la Figura 1.

3. Materials:

- Béns patrimonials: immobles, mobiliari, instruments, arxius, uniformes, material didàctic, assegurances.

- Màrqueting: patrocinadors, propaganda, promoció i vendes.

Roda també remarca com la importància que el voluntariat i el treball altruista havia exercit en tots els aspectes logístics fins a finals del segle $\mathrm{xx}$, ha anat virant cap a una organització més estructurada i professionalitzada emulant el món empresarial. Les juntes directives actuals solen estar integrades per músics, no músics, joves i persones de 
més edat per tal de crear un equip homogeni que treballi en la consecució d'un objectiu comú que és la millora i el progrés tant artístic-musical com social de la societat musical i dels seus músics.

Si ens centrem en la vessant merament musical trobem que el repertori bandístic va experimentar un canvi significatiu especialment a partir de les últimes dècades del segle $x x$. Fins al moment el repertori bandístic estava conformat per arranjaments d'obres orquestrals i la música original per banda tenia sobretot un caràcter regionalista o folklòric (Pascual-Vilaplana, 2011). Amb els anys s'ha aconseguit internacionalitzar la composició de música bandística, i s'ha creat un repertori original i propi, en el que els compositors s'han fixat en les particularitats d'aquestes agrupacions i les il.limitades possibilitats tímbriques dels instruments que les integren. Seguint aquesta internacionalització, les plantilles de les bandes també s'han anat modificant i per això tal i com afirma Pascual-Vilaplana (2011) la base ideal d'una banda podria estar conformada per 1 Flautí, 2 Flautes, 2 Oboès, 1 Corn Anglès, 2 Fagots, 1 Requint, uns 14 Clarinets (un d'ells Cl. Alt), 1 Clarinet Baix, 2 Saxos Alts, 2 Saxs Tenors, 1 Saxo Baríton, 5 Trompes, 3 Trompetes, 2 Fiscorns (o Cornetes), 3 Trombons, 1 Trombó Baix, 2 Bombardins, 3 Tubes, 1 o 2 Contrabaixos, 1 Timbaler i 4 Percussionistes (mínim). Atenent a les exigències de cada repertori a aquesta plantilla caldria incorporar ocasionalment nous instruments com saxo soprano, violoncels, piano, arpa... D'aquesta forma els compositors tindran una gran llibertat a I'hora de crear noves partitures i podran extreure el màxim rendiment tant tímbric com tècnic $i$ musical d'aquesta tipologia d'agrupacions.

La transformació del repertori bandístic es troba estretament relacionada amb una formació cada vegada més professionalitzada, en la que els professors de les escoles de música i els directors encarregats de l'ensenyament instrumental i del lideratge de cada agrupació, respectivament, tenen uns estudis musicals específics que permetran progressar i millorar el nivell artístic-musical tant a nivell individual com col-lectiu, però sense oblidar el caràcter amateur que impregna l'associacionisme bandístic (Morant, 2017).

Pel que fa al cens coral a Catalunya, en l'actualitat no existeix un registre oficial que aglutini el nombre exacte de corals i cantaires que conformen aquest fenomen, però a partir de les dades ofertes per les diferents federacions s'estima que hi hauria al voltant de 900 agrupacions amb més de 35.000 cantaires, distribuïts d'acord amb la Figura 2. 
Figura 2. Estimació de corals existents a Catalunya
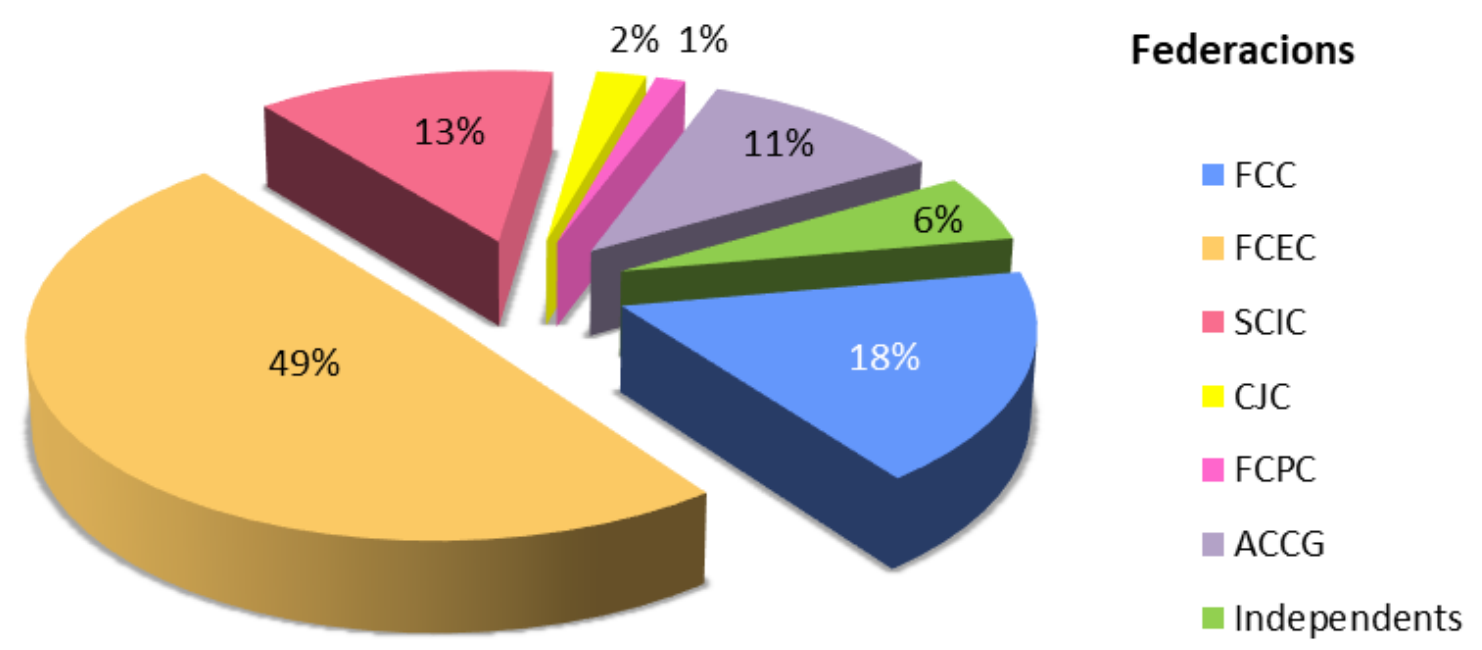

La Federació de Cors de Clavé (FCC) representa més de 200 entitats corals formades per uns 5.600 cantaires, que s'organitzen en 9 delegacions comarcals (Federació Cors Clavé, 2019). La Federació Catalana d'Entitats Corals (FCEC) està formada per uns 30.000 components distribuïts en més de 450 corals, l'organització gira entorn a 11 demarcacions territorials $\mathrm{i}$ els següents departaments $\mathrm{i}$ comissions de treball: cant gregorià, cors universitaris, cors de persones majors, cors gospel, espai jove i famílies corals (Federació Catalana d'Entitats Corals, 2019). El Secretariat d'Corals Infantils de Catalunya (SCIC) acull 120 agrupacions formades per un total de 3.000 membres, d'edats que oscil.len entre $4 \mathrm{i}$ 16 anys (Secretariat de Corals Infantils de Catalunya, 2019). La Federació de Corals Joves de Catalunya (FCJC) agrupa un total de 24 corals integrades per més de 500 joves (Federació de Corals Joves de Catalunya, 2019). La Federació Catalana de Pueri Cantores (FCPC) la conformen 13 cors i escolanies (Federació Catalana de Pueri Cantores, 2019). La confederació Moviment Coral Català (MCC) l'integren les corals associades a: la Federació de Pueri Cantores, la Federació de Cors Joves de Catalunya, la Federació dels Cors de Clavé, el Secretariat de Corals Infantils de Catalunya, la Federació dels Cors de Clavé de la Catalunya Nord, I'Agrupació Coral de les Comarques Gironines i I'Associació Musical de Mestres Directors, aquesta última com a membre adherit. Totes aquestes entitats agrupen més de 700 organitzacions corals i uns 30.000 cantaires (Moviment Coral Català, 2019). Finalment, la Federació Coral de Girona agrupa un total de més de 100 entitats vocals.

\section{A mode de conclusió}

L'elevada quantitat tant de bandes com de corals, distribuïdes per tota la Comunitat Valenciana i Catalunya, respectivament, fa impossible poder establir uns trets característics generals, ja que cada formació, depenent de multitud de factors com ara el nombre d'integrants, els objectius artístic-musicals que es proposen, les característiques de cada població, els seus recursos econòmics, etc., es pot considerar com a única i irrepetible. Però el que sí que comparteixen totes elles és la seva funció sociocultural: les agrupacions musicals actuals, a més d'oferir oci i l'entreteniment com passava al segle XIX, s'han refermat i consolidat, convertint-se en un referent identitari, cultural, social, educatiu i patrimonial de primer ordre tant a nivell local, com nacional $i$, fins i tot, internacional. El treball que s'exerceix en aquestes agrupacions juntament amb la realització de concerts, cercaviles, 
certàmens, etc., contribueixen dia a dia al desenvolupament de cada societat, oferint una àmplia oferta d'educació musical no formal de qualitat, democratitzant un repertori musical variat tant culte com popular, augmentant el bagatge cultural dels individus, participant en festes i tradicions, etc. D'acord amb Pascual-Vilaplana (2017, p. 1), les agrupacions musicals són «un manantial de recursos humanos en donde se entremezclan la educación, la sociabilidad y el arte».

A més, els músics integrants que conformen les bandes i les corals obtenen múltiples beneficis personals i interpersonals, ja que no només reben una formació musical no formal, sinó que també desenvolupen una infinitat de competències de tipus cognitiu i socioemocional, és a dir, el fet de formar part d'una agrupació musical comporta el desenvolupament de competències afectives com són la gestió emocional, les competències socials, l'autoestima; d'una banda a causa del treball en equip implícit i per l'altre per la temàtica de les agrupacions, ja que la música per si mateixa ja educa les emocions (Bisquerra i Bisquerra, 2012; Oriola, 2017). El treball col-lectiu que es porta a terme, d'acord amb Cohen (1999), s'ha convertit en part de la cultura pròpia de cada territori i de la idiosincràsia de la seva societat. A la Comunitat Valenciana no es concep cap poble sense la seva respectiva banda de música i el mateix passa a Catalunya amb les corals, són patrimoni sociocultural de cada població, els seus habitants se senten identificats amb elles i com afirma Gustems (2001, p. 86) «tant de bo en el futur la humanitat sàpiga aprofitar la presència creixent de la música al nostre món i contribueixi d'aquesta manera a una major felicitat».

\section{Referències}

Adam, B. (1986) Las Bandas de Música en el Mundo. Madrid, Sol Editorial.

Arnabat, R., i Ferré, X. (2017) «Evolución histórica de los ateneos en Catalunya», Historia contemporánea, 55, p. 383-480.

Artís, P. (1990) El cant coral a Catalunya (1891-1979). Barcelona, Barcino.

Asensi, E. (2010) El fenomen de les bandes de música valencianes en la cultura del segle XIX $i$ principi del XX. Tesi doctoral. València, Universitat de València.

Asensi, E. (2013) Música, mestre! Les bandes valencianes en el tombant del segle XIX. València, Publicacions Universitat de València.

Astruells, S. (2003) La banda municipal de Valencia y su aportación a la historia de la música valenciana. Tesi doctoral. València, Universitat de València.

Aviñoa, X. (2000) «La vida musical vuitcentista». A X. Aviñoa (Dir.), Història de la Música Catalana, Valenciana i Balear. Del Romanticisme al Nacionalisme, Vol. 3. Barcelona, Edicions 62, p. 13-55.

Aviñoa, X. (2009) «El cant coral als segles XIX i XX». Catalan Historical Review, 2, p. 203-212.

Baltá, P. (2011) «Elogi de la feina ben feta dels Cors de Clavé». Fulls Candelians, 4, p. 1-4. Recuperat de http: http://www.fundaciocandel.org/doc/fulls_candelians _04_cors_clave.pdf [accés: 3.7.2019]

Benavides, L., i Pérez, P. (2002) «Las mejoras en la enseñanza dentro del programa MUSE de la Fundación Yehudi Menuhin». Arte, Individuo y Sociedad, Annex I, p. 319-326.

Bisquerra, R., i Bisquerra, A. (2012) «Música i Educació emocional». Guix, 385, p. 12-16.

Bonastre, F., i Cortés, F. (Coords.) (2009) Història Crítica de la Música Catalana. Bellaterra, Publicacions UAB. 
Calderón-Garrido, D., Martín-Piñol, C., Gustems-Carnicer, J., i Portela-Fontán, A. (2018) «La influencia de las Artes como motor de bienestar: un estudio exploratorio». Arte, Individuo y Sociedad, 30 (1), p. 77-93. DOI: http://dx.doi.org/10.5209/ARIS.56350

Carbonell, J. (2000a) «El cant coral». A X. Aviñoa (Dir.), Història de la Música Catalana, Valenciana i Balear. Del Romanticisme al Nacionalisme, Vol. 3. Barcelona, Edicions 62, p. 147-186.

Carbonell, J. (2000b) Josep Anselm Clavé i el naixement del cant coral a Catalunya (18501874). Cabrera de Mar, Galerada.

Carbonell, J. (2003) «Aportaciones al estudio de la sociabilidad coral en la España contemporánea». Hispania, 63 (214), p. 485-503.

Cohen, R. S. (1997) The Musical Society Community Bands of Valencia, Spain: A global study of their administration, instrumentation, repertoire and performance activities. Tesi doctoral inédita. Chicago, Northwestern University.

Cohen, R. S. (1999) «Community Ensemble Music as a Means of Cultural Expression in the Catalan-Speaking Autonomies of Spain». A D. Dougherty i M. M. Azeveda (Eds.), Multicultural Iberia: Language, Literature and Music. Berkeley, University of California Press, p. 230-251.

Craveri, B. (2018) Los últimos libertinos. Madrid, Siruela

Cucó, J. (Dir.) (1993) Músicos y festeros valencianos. València, Generalitat Valenciana.

De la Ossa, M. A. (2009) La música en la guerra civil española. Tesi doctoral. Cuenca, Universidad de Castilla-La Mancha.

Federació Catalana d'Entitats Corals. (2019) Portal de la Federació Catalana d'Entitats Corals. Recuperat de http://www.fcec.cat/ [accés: 3.7.2019]

Federació Catalana de Pueri Cantores. (2019) Portal de la Federació Catalana de Pueri Cantores. Recuperat de http://www.puericantores.cat [accés: 3.7.2019]

Federació Coral de Girona. (2019) Portal de la Federació Coral de Girona. Recuperat de https://agrupaciocoraldelescomarquesdegirona.org/presentacio/ [accés: 3.7.2019]

Federació Corals Joves de Catalunya. (2019) Corals Joves de Catalunya. Recuperat de http://coralsjoves.cat/ [accés: 3.7.2019]

Federació de Cors de Clavé. (2019) Portal de la Federació de Cors de Clavé. Recuperado de http://www.josepanselmclave.cat/ [accés: 3.7.2019]

Federació Societats Musicals de la Comunitat Valenciana. (2019) Portal de la Federació Societats Musicals de la Comunitat Valenciana. Recuperat de http://www.fsmcv.org/ [accés: 3.7.2019]

Fernández, N., Corraliza, J. A., i Ferreras, S. (2017) «Las agrupaciones corales en España: espacios para la convivencia y la educación musical». Revista Internacional de Educación Musical, 5, p. 17-29. DOI: 10.12967/RIEM-2017-5-p017-029

Ferrer, R. (2011) El cant coral infantil i juvenil educa en valors, hàbits i competències. Tesi doctoral. Girona, Universitat de Girona.

Guhn, M., Emerson, S. D., i Gouzouasis, P. (2019) «A Population-Level Analysis of Associations Between School Music Participation and Academic Achievement». Journal of Educational Psychology. http://dx.doi.org/10.1037/edu0000376 [accés: 4.7.2019]

Gustems, J. (2001) «L'entorn sonor, un element educatiu de primer ordre». Temps d'Educació, 25, p. 77-88. Recuperat de https://www.raco.cat/index.php/ TempsEducacio/article/view/126238/247095 [accés: 22.5.2019] 
Hallam, S., y Creech, A. (Eds.). (2010) Music Education in the 21st Century in the United Kingdom. Londres, Institute of Education, University of London.

Leal, J. de D. (Ed.). (2014). Las Bandas de Música de la Comunitat Valenciana. València, Gules.

Merriam, A. P. (1992) The Anthropology of Music. Evanston, II: Northwestern University Press. (Treball original publicat el 1964).

Ministerio de Educación, Cultura y Deporte. (2016) Explotación Estadística de las Bases de Datos de Recursos Musicales y de la Danza. Recuperat de https://bit.ly/2J2ko29 [accés: 2.7.2019]

Moviment Coral Català. (2019) Moviment Coral Català. Recuperat de http://www.mcc.cat/ [accés: 3.7.2019]

Morant, R. (2017) «Bandas, escuelas y músicos valencianos: del amateurismo al mercado de trabajo». Estudios bandísticos, 1, p. 147-150.

Narváez, M. (2005) L'Orfeó Català, cant coral i catalanisme (1891-1951). Tesi doctoral. Barcelona, Universitat de Barcelona.

Oriola, F. (2010) «Els concursos bandístics a la Vall d'Albaida: els casos d'Ontinyent i Albaida». Quadrivium, 1, p. 1-6.

Oriola, F. (2011) Temps de músics i capellans. Valencia, Federació de Societats Musicals de la Comunitat Valenciana.

Oriola, S. (2017) Las agrupaciones musicales juveniles y su contribución al desarrollo de competencias socioemocionales. El fenómeno de las bandas en la Comunidad Valenciana y los coros en Cataluña. Tesi doctoral. Lleida, Universitat de Lleida. Recuperat de http://hdl.handle.net/10803/405944 [accés: 20.7.2018]

Oriola, S.; Gustems, J., i Filella, G. (2019) «Las bandas juveniles de la Com. Valenciana: medio siglo promoviendo la educación musical no formal y desarrollando competencias socioemocionales». ArtsEduca, 23, p. 36-51. Recuperat de http://www.e-revistes.uji.es/index.php/artseduca/article/view/ 3873 [accés: 5.7.2019]

Pascual-Vilaplana, J. R. (2011) Las bandas de música: un vehículo de cultura para el siglo. Recuperat de https://www.pascualvilaplana.com/en/articulos/art//15/ pag/8 [accés: 4.7.2019]

Pascual-Vilaplana, J. R. (2017) Los ecos del viento. Recuperat de https://www.pascualvilaplana.com/en/articulos/art/encuentros/53/pag/3 [accés: 4.7.2019]

Reyes, M. C. (2010) El rendimiento académico de los alumnos de primaria que cursan estudios artísticomusicales en la Comunidad Valenciana. Tesi doctoral. València, Universitat de València. Recuperat de http://hdl.handle.net/10803/81333 [accés: 21.7.2018]

Roda, J. (2001) «Les Bandes de Música: funció social, musical i pedagògica». Temps d'Educació, 25, p. 89-101. Recuperat de https://www.raco.cat/index.php /TempsEducacio/article /view/126239/262373 [accés: 22.5.2019]

Secretariat de Corals Infantils de Catalunya. (2019) Portal del Secretariat de Corals Infantils de Catalunya. Recuperat de http://www.scic.cat/ [accés: 8.8.2019] 


\section{Agrupaciones musicales en la Comunidad Valenciana y Cataluña: agentes para el desarrollo sociocultural}

Resumen: Las bandas en la Comunidad Valenciana y las corales en Cataluña conforman dos fenómenos de asociacionismo musical amateur referentes tanto a nivel nacional como internacional. El presente artículo, realizado a partir de una exhaustiva revisión bibliográfica de tipo multidisciplinar, consiste en un estudio descriptivo con el que se pretende mostrar cómo las funciones socioculturales que han desempeñado ambos tipos de agrupaciones, desde sus orígenes hasta la actualidad, han ido en aumento tanto en cantidad como en calidad. Para ello se ha realizado una retrospectiva histórica en la que se puede observar cómo ha ido evolucionando dicho fenómeno hasta llegar al momento de esplendor actual. Todo este progreso viene avalado por la existencia de 547 bandas en la Comunidad Valenciana y más de 900 corales en Cataluña, las cuales se han convertido con los años en un referente identitario, cultural, social, educativo y patrimonial de primer orden.

Palabras clave: Agrupaciones musicales, bandas, corales, desarrollo sociocultural.

\section{Les groupes musicaux de la Communauté valencienne et de la Catalogne: des agents pour le développement socioculturel}

Résumé: Les orchestres de la Communauté valencienne et les chorales de Catalogne constituent deux phénomènes d'associationnisme musical amateur de référence, tant au niveau national qu'international. Cet article, élaboré à partir d'un examen bibliographique exhaustif de nature multidisciplinaire, consiste en une étude descriptive visant à montrer comment les fonctions socioculturelles exercées par les deux types de groupes, de leurs origines jusqu'à nos jours, se sont multipliées, d'un point de vue quantitatif comme qualitatif. À cette fin, une rétrospective historique a été réalisée, dans laquelle on peut observer comment ce phénomène a évolué jusqu'à atteindre toute sa splendeur actuelle. Tous ces progrès sont garantis par l'existence de 547 orchestres dans la Communauté valencienne et de plus de 900 chorales en Catalogne, qui sont devenus au fil du temps une référence identitaire, culturelle, sociale, éducative et patrimoniale de premier ordre.

Mots clés: Groupes musicaux, orchestres, chorales, développement socioculturel

\section{Music groups in Valencia and Catalonia: agents for socio-cultural development}

Abstract: Music groups from Valencia and choirs from Catalonia are two phenomena of amateur musical associationism that are references both nationally and internationally. This article, based on an exhaustive multidisciplinary bibliographical review, is a descriptive study that aims to show how the sociocultural functions that these two types of groups play have progressively increased in quantity and quality since the beginnings of the phenomenon to the present. We carried out a historical retrospective review showing how these associative musical phenomena have evolved in each region from their origins until their current peak and splendour. This progress is supported by 547 bands in Valencia and more than 900 choirs in Catalonia, which have become over the years a cultural, social, educational and patrimonial reference of identity.

Keywords: Music groups, bands, choirs, sociocultural development. 